\title{
DIREITO E DEMOCRACIA - O SIGNIFICADO DAS LEIS E DO LEGISLATIVO NA TEORIA DA DEMOCRACIA
}

\author{
LAW AND DEMOCRACY - THE SIGNIFICANCE OF THE LAWS \\ AND THE LEGISLATURE IN THE THEORY OF DEMOCRACY \\ Cristiane Fernandes de Souza ${ }^{1}$ \\ Paulo de Tarso Fernandes de Souza ${ }^{1}$
}

\begin{abstract}
Recebido em: 04/07/2016 Aceito em: 06/07/2017

casfortaleza@hotmail.com paulodetarso.ce@hotmail.com
\end{abstract}

Resumo: O objetivo geral desse artigo consiste na análise do significativo da lei e do legislativo na teoria da democracia. Os objetivos específicos abrangem a identificação da importância da lei e do legislativo na compatibilização da liberdade e da igualdade, o exame da legitimidade democrática do parlamento e a indicação de medidas que contribuam para a superação da crise do sistema representativo. Desse modo, a democracia está fundada na liberdade e na igualdade. A natureza social do ser humano, todavia, indica que a liberdade como autodeterminação precisa ser entendida sob uma perspectiva coletiva, tendo em vista que a igualdade estende a autonomia moral para todos os integrantes da sociedade. Como consequência, a liberdade inclui a participação, em igualdade de condições, nos processos coletivos de tomada de decisão destinados a estabelecer as normas que devem reger a conduta dos membros da comunidade. Nesse contexto, a lei corresponde a um instrumento de defesa contra o arbítrio e o legislativo é o poder constituído detentor de maior legitimidade, na medida que é estruturado para representar a pluralidade social, é composto por representantes eleitos diretamente pelo povo e sujeitos à responsabilidade política e promover a autodeterminação coletiva com a elaboração das leis. A crise do sistema representativo deve ser solucionada através do aperfeiçoamento dos mecanismos de representação, da promoção de uma cultura democrática e da viabilização de uma maior participação política popular.

Palavras-chave: Teoria da democracia. Leis. Legislativo.

\begin{abstract}
The general aim of this article consists in an analysis of the significance of the law end legislature in the theory of democracy. The specific aims embrace the identification of the importance of the law and the legislature in the compatibility of freedom and equality, exam of the democratic legitimacy of the parliament and indication of the measures that contribute to the solution of the representative system's crisis. Therefore, democracy is grounded on freedom and equality. The social nature of human beings, however, indicate that freedom as self-determination ought to be understood from a collective perspective, taking into account that equality extends moral autonomy to all persons that integrate the society. Accordingly, freedom embraces the participation, in equal terms, in the decision-making processes destined to stablish the norms, which ought to rule the conduct of the community's members. In this context, the law corresponds to an instrument of defence against arbitrariness and the parliament is the constituted power that has the higher democratic legitimacy, insofar as it is structured to represent the political plurality of society, is composed by representatives directly elected by the people and subjected to political liability and promotes the collective selfdetermination with the elaboration of laws. The crisis of the representative system ought to be solved by the improvement of the representation mechanisms, promotion of a democratic culture and exercise of the political power by the people.
\end{abstract}

Keywords: Theory of democracy. Laws. Legislature.

\section{CONSIDERAÇÕES INICIAIS}

\footnotetext{
${ }^{1}$ Universidade Federal do Ceará - UFC - Fortaleza - Ceará- Brasil
} 
$\mathrm{Na}$ história do pensamento político ocidental, as leis e o legislativo ocuparam, tradicionalmente, lugar de destaque nas teorias da democracia, tendo em vista que a lei é compreendida como a expressão da vontade coletiva dos cidadãos e o poder legislativo é atribuído ao povo ou a representantes eleitos diretamente. Na realidade atual do direito brasileiro, essa teorização pode ser encontrada na Constituição da República Federativa do Brasil, de 05 de outubro de 1988, documento elaborado, no plano discursivo, com a ousada pretensão de "reinserir" - ou, mais precisamente, em virtude do histórico de desigualdade social, de "inserir" - o país na "normalidade institucional" da democracia. Desse modo, logo no artigo $1^{\circ}$, caput e parágrafo único, o texto constitucional assegura expressamente a estruturação de um Estado Democrático de Direito e garante ao povo a titularidade e o exercício direto ou por meio de representantes de todo o poder político.

Os vinte e sete anos de vigência da Constituição Federal de 1988, todavia, parecem indicar a cisão irreversível entre as dimensões normativa e fática da democracia e comprovar o distanciamento da ética em relação à política e ao direito. A atuação do legislativo foi e continua a ser marcada por omissões e escândalos de corrupção. As leis, por sua vez, em muitos casos, não expressam a vontade popular. É válido ressaltar que essa crise de legitimidade da representação política ocorre em vários países, tenham eles uma democracia consolidada ou não (MIGUEL, 2000). No Brasil, observa-se que a população, em geral, considera que os políticos, os partidos e o Parlamento não representam os interesses dos cidadãos (MOISÉS, 1995). Recente pesquisa divulgada pela Fundação Getúlio Vargas revela que a proporção de pessoas que afirmam confiar nos partidos políticos caiu de 7\%, em 2014, para 5\% em 2015, e no Congresso Nacional o índice permaneceu em 15\% (BOCHINI, 2015). Nesse contexto, consideramos ser importante analisar o significado da lei e do legislativo na democracia, com o intuito de contribuir para as discussões pertinentes a esse assunto no âmbito da filosofia do direito e do direito constitucional.

Para desempenhar esse objetivo, dividimos o presente artigo em cinco partes principais. Na primeira parte, sustentamos que a liberdade e a igualdade são os dois pilares fundamentais da democracia, desde as primeiras formulações na Grécia antiga, e conferimos um mínimo de conteúdo semântico às palavras "liberdade" e "igualdade", para viabilizar as abordagens seguintes. Na segunda parte, partimos da ideia de que o ser humano é, simultaneamente, um animal social, moral e normativo, e enfrentamos o problema da compatibilização da liberdade e da igualdade na democracia. Na terceira e na quarta parte, analisamos a compatibilidade entre o legislativo e a democracia e buscamos as razões aptas a conferir legitimidade democrática ao Parlamento. Na quinta parte, reconhecemos a crise do sistema representativo tradicional e propomos algumas soluções.

\section{A LIBERDADE E A IGUALDADE COMO FUNDAMENTOS DA DEMOCRACIA}


A democracia está associada à liberdade e à igualdade desde a antiguidade clássica até os dias de hoje. Na Grécia antiga, o povo ${ }^{2}$ podia ser considerado livre, tendo em vista que se reunia entre iguais na praça pública (Ágora) com o objetivo de elaborar as leis que regiam a vida em comunidade (GOYARD-FABRE, 2003). Na idade moderna, as teorias desenvolvidas por diversos filósofos do direito reforçaram essa ideia. Para Jean-Jacques Rousseau (2013), a liberdade corresponde à submissão às leis, na medida que a lei representa a própria vontade geral do povo. Immanuel Kant (1986) identifica liberdade com autonomia e a universaliza, através da noção de reino dos fins, para todos os seres igualmente racionais, com respaldo na ideia de dignidade. No século XX, Hans Kelsen (2000) expressamente sustenta que a democracia promove a síntese entre a liberdade e a igualdade, enquanto dois instintos básicos do ser humano. Embora diversos teóricos, ao longo da história da filosofia do direito, não tenham realizado uma defesa do ideal democrático, contribuíram para a construção gradual dos princípios de liberdade e igualdade como dois pilares fundamentais do que hoje entendemos por democracia (GOYARD-FABRE, 2003). Por essa razão, uma reflexão sobre a lei e o legislativo deve partir desse ponto.

A liberdade possui duas dimensões interdependentes que se influenciam e se completam. A liberdade como autodeterminação ou livre-arbítrio consiste na capacidade intelectual do ser humano de determinar o próprio agir e realizar as próprias escolhas de forma consciente e por intermédio de um processo de reflexão e ponderação de valores (FERNANDEZ; FERNANDEZ, 2008). Essa dimensão da liberdade implica a autonomia moral, tendo em vista que o indivíduo detém a capacidade para cultivar os princípios morais utilizados na tomada de decisão (DAHL, 1989). Desse modo, embora o raciocínio e o comportamento humanos sejam desenvolvidos sobre uma base fixada pela herança genética e sob a influência constante do inconsciente, o processo de adaptação evolutiva e a seleção natural viabilizaram a construção de uma estrutura biopsicológica que conferiu ao ser humano, através da consciência e da razão, a capacidade intelectual de organizar e interpretar as demandas internas, com o intuito de precisar o modo concreto de agir para alcançar finalidades estabelecidas (FERNANDEZ; FERNANDEZ, 2008).

A liberdade como possibilidade real de agir corresponde ao poder de o ser humano atuar em consonância com a própria vontade, de materializar as decisões tomadas, com o intuito de alcançar a autossuficiência e a autorrealização. Essa segunda dimensão da liberdade demanda a estruturação das condições sociais necessárias para que o indivíduo possa agir livremente, o que inclui o enfrentamento de constrições naturais (COMPARATO, 2010). O ser humano é situado em posições sociais (direitos) que o permitem praticar certos atos comissivos e omissivos e exigir dos demais membros da sociedade a adoção de condutas positivas e negativas. A liberdade requer a construção de uma esfera dentro da qual a pessoa esteja livre de intervenções arbitrárias (FERNANDEZ; FERNANDEZ, 2008), que compreendem as barreiras e os obstáculos indevidamente impostos por

\footnotetext{
${ }^{2} \mathrm{Na}$ Grécia antiga, o povo representava apenas uma pequena parte da população, com a exclusão de mulheres, escravos e estrangeiros (DAHL, 1989). Embora essa peculiaridade seja analisada abaixo, consideramos importante chamar a atenção do leitor para esse ponto, desde logo.
} 
outras pessoas, de forma intencional ou não intencional, bem como os atos de manipulação e opressão (CARTER, 2015).

A igualdade significa que todos os seres humanos possuem um valor moral mínimo denominado de dignidade, na medida que partilham um conjunto de características básicas. A dignidade requer que todos sejam tratados com igual respeito e consideração (DWORKIN, 2013), independentemente das diferenças culturais, biológicas e patrimoniais (COMPARATO, 2010). Dessa maneira, afirmar que as pessoas são iguais consiste em sustentar que são semelhantes em relação a aspectos relevantes, apesar das diferenças existentes (GOSEPASH, 2015). A observância adequada da igualdade exige a adoção de medidas capazes de combater as desigualdades sociais que violam a dignidade e não guardam relação de causalidade com a conduta pessoal do indivíduo (COMPARATO, 2010). Por essa razão, dispensar o mesmo tratamento a todos não significa necessariamente promover a justiça. A partir de uma visão equitativa, aqueles que se encontram em situação igual devem ser tratados igualmente e aqueles que se encontram em situações desiguais devem ser tratados desigualmente na medida proporcional das desigualdades (ARISTÓTELES, 1991).

No mesmo sentido, a igualdade implica o reconhecimento de autonomia moral para a larga maioria das pessoas que integram determinada sociedade ${ }^{3}$. O indivíduo moralmente autônomo é considerado suficientemente qualificado, independentemente de conhecimentos técnico-científicos, para governar a si mesmo e ser juiz dos próprios interesses. Como consequência, nenhuma autoridade paternalista pode substituir o ser moralmente autônomo no que concerne à tomada de decisão. Sobre esse aspecto, grande parte das lutas históricas pela igualdade democrática correspondeu a tentativas de reconhecimento de autonomia moral por parte de grupos sociais formalmente excluídos da vida política. São exemplos, a sujeição do escravo à autoridade paterna do proprietário e a sujeição da mulher à autoridade paterna do marido ${ }^{4}$.

\section{A IMPORTÂNCIA DA LEI E DO PODER LEGISLATIVO: DA NATUREZA SOCIAL DO SER HUMANO À COMPATIBILIZAÇÃO DA LIBERDADE E DA IGUALDADE NA DEMOCRACIA}

As vantagens existentes na vida humana coletiva realizaram pressões evolucionárias que selecionaram determinadas características e incentivaram a sociabilidade. As características escolhidas podem ser divididas em dois grupos. Um primeiro grupo consistiu nos sentimentos negativos de medo e ansiedade, quando a prole era ameaçada ou separada dos pais, e nos sentimentos positivos de prazer e alívio, decorrentes do fim da ameaça ou do reencontro entre pais e prole. Um segundo grupo permitiu o aumento da aptidão para o aprendizado e para a memória relacionada à dor e ao prazer e o conhecimento da forma como os outros integrantes do grupo se comportavam, o que elevou a capacidade de antecipar problemas e planejar com maior efetividade.

\footnotetext{
${ }^{3}$ Optamos por afirmar que a autonomia moral é reconhecida à "larga maioria das pessoas", e não a "todas as pessoas", porque entendemos que a ausência de autonomia moral pode ser compatível com a democracia, desde que se reduza a uma pequena parcela de casos, a exemplo das crianças (DAHL, 1989).

${ }^{4}$ Sobre os argumentos relacionados com a defesa de uma presença equilibrada entre homens e mulheres na política, ver (AQUINO DE SOUZA, 2015).
} 
Nesse contexto, a estrutura neural que fomentava o autocuidado e a procura pelo bem-estar próprio foi gradativamente reformulada para abranger, do mesmo modo, o cuidado e o bem-estar do outro. No início, o outro correspondeu apenas à prole, mas, em seguida, houve uma ampliação proporcional à expansão do círculo de interação social até abranger parentes, companheiras e companheiros, amigas e amigos e até estranhos (CHURCHLAND, 2011).

A sociabilidade conferiu suporte ao desejo de pertencer a um grupo social e ao desenvolvimento de uma consciência ligada a práticas sociais (conjunto de respostas sociais pelo aprendizado), fortemente reguladas por emoções e por um sistema de aprovação e desaprovação estruturado por normas. O sistema de recompensa negativo regula a dor, o medo e a ansiedade e responde à desaprovação, enquanto o sistema de recompensa positivo regula o prazer e responde à aprovação e à afeição. Desse modo, a ideia de apego (vínculo emocional) subscrita pelo prazer da companhia e pela dor da separação forma a plataforma neural da moralidade (CHURCHLAND, 2011). Nesse sentido, em decorrência da natureza social, o ser humano pode também ser entendido como um animal: normativo, tendo em vista que as pessoas criam e seguem normas através de práticas sociais, o que caracteriza uma natureza normativa; e moral, na medida que a estrutura biológica e psicológica permite que, sobre as predeterminações genéticas, seja desenvolvida uma natureza constituída de atos, hábitos e valores socialmente compartilhados, denominada de natureza moral (FERNANDEZ; FERNANDEZ, 2008).

A natureza humana social gera um problema de ordem prática para a democracia. De um lado, o princípio da liberdade estabelece que o indivíduo é livre por deter a capacidade de determinar o próprio agir, quando realiza as próprias escolhas morais e cria as próprias normas. Dessa maneira, cada ser humano detém um poder legislativo individual. De outro lado, o princípio da igualdade estende, pela autonomia moral, a capacidade de autodeterminação para a grande maioria dos integrantes de uma sociedade. Como as pessoas realizam juízos morais com fundamento nas experiências pessoais, na percepção que possuem da realidade e no conhecimento acumulado, é bastante provável que nutram concepções diversas sobre certo e errado, justo e injusto, políticas adequadas, direitos existentes e formas de distribuição de bens e encargos. Esse quadro viabiliza o surgimento de dificuldades na definição das normas que devem reger a vida humana em sociedade (WALDRON, 1999). Assim, a síntese dos princípios de liberdade e igualdade promovida pela democracia cria a necessidade de saber como seres humanos igualmente livres podem viver em coletividade (KELSEN, 2000).

A resolução desse impasse pode ser encontrada em um raciocínio desenvolvido a partir da própria noção de sociabilidade. Nesse sentido, a natureza social do ser humano indica que a moralidade, as normas sociais e o direito integram uma realidade social construída por meio de consensos públicos formados pela contínua dinâmica das relações humanas (BARRET; et al, 2012). Desse modo, o alicerce dos regimes políticos, democráticos ou não democráticos, e dos sistemas jurídicos é formado pela vontade coletiva definida pelo princípio majoritário. A singularidade da democracia reside no reconhecimento expresso desse fato e na consequente atribuição do poder político ao povo, entendido como coletividade. Portanto, em uma sociedade democrática, a soberania 
popular reside na autonomia política e na capacidade de autogoverno pelas quais o povo exerce o poder legislativo e dita para si as leis que regerão a conduta humana (GOYARD-FABRE, 2003).

Para que pessoas igualmente livres e moralmente autônomas possam viver em sociedade, é importante que adotem um procedimento capaz de viabilizar a tomada de decisão no âmbito público e a formação de uma vontade coletiva vinculante, com o intuito de compatibilizar a liberdade e a igualdade de cada um na construção coletiva e racional das normas sociais e da moralidade (DAHL, 1989). Por essas razões, a liberdade pode ser também compreendida como a participação, em igualdade de condições, nos processos deliberativos públicos (ROUSSEAU, 2013). Nesse contexto, as leis possuem o importante papel de identificar, de modo relativamente claro e expresso, as opções realizadas por uma comunidade e, nesse sentido, reduzir a possibilidade de arbítrio, em especial, nos atos praticados pelos agentes estatais, pela diminuição da margem de discricionariedade e subjetividade dos juízos morais (WALDRON, 1999).

A ideia de que cada pessoa pode agir de acordo com as concepções pessoais de justiça, moralidade e correção detém o potencial de inviabilizar a convivência em sociedade ou de abrir espaço para o arbítrio, mesmo que a ação seja guiada por uma sincera e honesta tentativa de ser ético. É necessário visualizar os outros como detentores de mentes, intelectos e juízos morais próprios. Desse modo, no momento em que alguém pensa em justiça e nutre a confiança na objetividade das próprias conclusões, deve também ter em mente que outra pessoa pode igualmente teorizar sobre justiça e cultivar igual confiança na objetividade das conclusões que alcançar. A sociedade precisa adotar respostas para questões morais de relevância pública e uma forma de identificá-las publicamente, com o objetivo de permitir ou, pelo menos, facilitar a normatização da conduta humana. Em uma democracia, a lei é o instrumento adequado para abrigar e identificar publicamente essas respostas (WALDRON, 1999).

\section{A REPRESENTAÇÃO POLÍTICA E A LEGITIMIDADE DEMOCRÁTICA DO PARLAMENTO}

Na Grécia antiga, a democracia podia ser entendida como direta, na medida que satisfazia a ideia de governo do povo ${ }^{5}$, pois os próprios cidadãos se reuniam em praça pública para deliberar sobre os assuntos de interesse geral da sociedade (GOYARD-FABRE, 2003). Desse modo, foram rejeitadas a criação de um sistema político de larga escala e a estruturação de um governo representativo estável. Em Roma, ainda na antiguidade, as instituições democráticas existentes eram as assembleias realizadas para eleger os magistrados e elaborar as leis. O crescimento territorial e populacional ocasionado pela expansão da república, contudo, impossibilitou que grande parte dos cidadãos romanos residentes em locais distantes das reuniões participassem ativamente da vida política. Como consequência, embora carecesse de reconhecimento teórico, a representação se tornou realidade e acabou por beneficiar de alguma maneira aqueles que podiam comparecer pessoalmente às deliberações (DAHL, 1989).

\footnotetext{
${ }^{5}$ Cabe salientar, novamente, que, na Grécia antiga, o povo representava apenas uma pequena parte da população, com a exclusão de mulheres, escravos e estrangeiros (DAHL, 1989).
} 
A prática da representação política começou a ser desenvolvida de forma mais consciente durante a Idade Média pela monarquia e pela aristocracia, especialmente, na Inglaterra e na Suécia. Nesse sentido, as assembleias eram convocadas pelos monarcas ou pelos integrantes da nobreza, com o objetivo de discutir questões de Estado, tais como receitas, guerras e sucessão real. Com o decorrer do tempo, os órgãos representativos foram divididos em duas câmaras: a casa dos nobres (house of lords) e a casa dos comuns (house of commons). Em seguida, durante a Guerra Civil Inglesa, os Levellers promoveram uma importante mudança no pensamento jurídico e político, tendo em vista que destacaram, expressamente, a necessidade de estabelecer a representação, quando reivindicaram mais privilégios estatais e maior responsabilidade do governo (DAHL, 1989). A partir desse instante, as contribuições começam a se aproximar da atual compreensão de representação política.

De acordo com Thomas Hobbes (2008), uma multidão de homens fundava a comunidade política através de cada um dos integrantes do grupo quando constituía um representante. Era a unidade do representante, e não dos representados, que permitia considerar uma multidão como uma só pessoa. Em sentido semelhante, John Locke (2003) entendia que o consenso da maioria, especialmente em matéria de tributação, deveria ser concedido pelos próprios integrantes do corpo coletivo ou pelos respectivos representantes. Conforme Montesquieu (2005), como a reunião de todos os cidadãos em praça pública era inviável nos Estados modernos, o povo deveria escolher representantes. Embora esses pensadores não tenham realizado uma defesa dos ideais democráticos, tal como hoje compreendidos, abriram caminho para que o pensamento segundo o qual a representação política é um instrumento necessário à prática democrática, a ponto de as democracias passarem a ser adjetivadas como "representativas" (DAHL, 1989).

Nas sociedades contemporâneas, a representação política corresponde a um elemento da teoria da democracia por três fatores principais. Em primeiro lugar, os Estados são extensos e populosos o suficiente para inviabilizar a reunião de todos os cidadãos em praça pública e um diálogo capaz de incorporar a integralidade dos interessados (MIGUEL, 2014). Em segundo lugar, a ampliação gradativa do conteúdo semântico das palavras povo e cidadão (GOYARD-FABRE, 2003), decorrente da reinterpretação do princípio de igualdade e a consequente inclusão social de grupos historicamente marginalizados - mulheres, pobres, trabalhadores, analfabetos e imigrantes -, intensificou essa dificuldade quantitativa. Em terceiro lugar, a possibilidade de exercício direto do poder foi sensivelmente reduzida pela significativa diminuição do tempo destinado à participação política, tendo em vista a necessidade de grande parte da população prover o próprio sustento pelo exercício de alguma atividade laboral (MIGUEL, 2014).

Nesse contexto, a representação política pode tanto refletir grupos e interesses preexistentes como produzir identidades coletivas com o estabelecimento de fronteiras entre os grupos social e politicamente relevantes, além de viabilizar a construção e a reconstrução permanente de interesses. Desse modo, desempenha papel central na estruturação das comunidades políticas, pois confere unidade e homogeneidade interna a um grupo social e o diferencia dos demais. Em um processo de sintetização, a representação política mantém o que une e minimiza o que separa, diferencia o fundamental do contingente e estabelece o cerne da comunidade política (MIGUEL, 2014). 
A representação política pode ser compreendida em sentido amplo e em sentido estrito. A representação política em sentido amplo abrange todos os agentes públicos, integrantes da administração pública direta e indireta e das três funções estatais (legislativo, executivo e judiciário), na medida que a condição de agente público depende do reconhecimento e do consentimento do povo (GOYARD-FABRE, 2003). Esse entendimento não significa, todavia, que todos os representantes políticos possuem a mesma legitimidade democrática. Nesse ponto, emerge a importância da representação política em sentido estrito, que corresponde ao corpo de representantes eleitos para integrarem o parlamento. A maior legitimidade do legislativo possui três fundamentos: o parlamento é constituído para representar a diversidade e reproduzir, proporcionalmente, as características da sociedade, com o intuito de assegurar o pluralismo e a representatividade das minorias; os parlamentares são escolhidos e, portanto, autorizados diretamente pelo povo, assim como estão sujeitos à prestação de contas e, como consequência, à responsabilização política perante os representados, principalmente, através de eleições periódicas (MIGUEL, 2014); e o legislativo detém o objetivo básico de viabilizar e institucionalizar a autonomia e a autodeterminação de um povo, enquanto coletividade política, por intermédio da realização das escolhas morais e da elaboração das leis que devem reger a vida em sociedade.

\section{A CRISE DO SISTEMA REPRESENTATIVO E A PARTICIPAÇÃO POLÍTICA POPULAR}

A prática do modelo ideal de representação política descrito no tópico anterior, contudo, apresentou e continua a apresentar distorções graves o bastante para gerar uma crise do sistema representativo que atinge o Parlamento e os partidos políticos e promove um déficit de legitimidade democrática capaz de comprometer a noção de governo do povo. As desigualdades sociais permitem que a unidade trazida pela representação política desqualifique os interesses e os valores de grupos sociais mais fracos (MIGUEL, 2014), principalmente, em países com forte herança escravista, como o Brasil (ALBUQUERQUE, 2008). Nesse contexto, a representação política se tornaria um instrumento aristocrático de exclusão, e não de inclusão, do povo (RANCIÈRE, 2014).

A resolução democrática da crise do sistema representativo tradicional exige medidas destinadas a corrigir as distorções apresentadas na representação política em sentido estrito (Parlamento) e, em especial, habilitar o povo para exercer a democracia. A correção das distorções da representação política em sentido estrito pode ser realizada por mecanismos que aprimorem a representação proporcional, com o intuito de assegurar a reprodução das principais características da sociedade e a representação de grupos minoritários ou excluídos. Nesse contexto, é possível citar, como exemplos, o fim do financiamento privado de campanhas políticas e as cotas eleitorais de gênero que buscam favorecer uma presença equilibrada de homens e mulheres na política. A habilitação do povo para o exercício da democracia requer o incentivo a uma cultura democrática por meio da educação - com a difusão dos valores de igualdade, liberdade, tolerância, respeito aos direitos das minorias -, a conscientização de direitos e deveres e o fornecimento de condições materiais mínimas para a participação política (MIGUEL, 2014). 
Embora a extensão dos Estados contemporâneos impeça a reunião de todos em praça pública, a contribuição da democracia grega consiste na ideia de que os assuntos públicos devem ser decididos pelo debate público. Nesse sentido, compete aos próprios cidadãos definirem e redefinirem os temas que devem ser submetidos à discussão pública. O povo, contudo, é uma unidade política ideal composta por diversos grupos sociais dotados de interesses próprios. Comumente, em virtude da complexidade subjetiva da existência humana, cada integrante da sociedade faz parte de mais de um grupo social, a depender do interesse que pretende defender. Portanto, dizer que compete ao povo definir os temas que precisam ser submetidos ao debate público e realizar escolhas morais significa sustentar que os diversos grupos sociais de interesse devem possuir a oportunidade de participar do debate público e das escolhas morais. Cabe aos próprios grupos sociais a inclusão e a exclusão de temas na agenda e no debate público, e não, necessariamente, apenas aos representantes eleitos (MIGUEL, 2014).

$\mathrm{Na}$ realização do debate público, os meios de comunicação ocupam lugar de destaque, em decorrência da centralidade que possuem na difusão de informações nas sociedades de massa contemporâneas e da detenção da capacidade de interferir na percepção que as pessoas possuem da realidade, na medida que selecionam e interpretam os fatos que consideram relevantes. Assim, a pauta dos assuntos que integram o debate público e a tomada de decisão pela formação da opinião pública são, em grande parte, condicionadas pela visibilidade conferida pela mídia. Em virtude da importância da esfera deliberativa pública para a democracia, os meios de comunicação devem ser estruturados para garantir a manifestação dos diversos grupos de interesses existentes na sociedade para que participem do debate público diretamente, com voz própria, a fim de viabilizar a formação da opinião pelo público a partir do embate de argumentos e visões de mundo. Nesse contexto, a democratização da mídia exige medidas como: a desconcentração da propriedade de empresas de comunicação; a limitação da influência do poder econômico; a reserva de tempo para movimentos sociais veicularem as respectivas posições; o incentivo ao jornalismo, ao rádio e à televisão comunitários; e o financiamento público para integrar ao debate grupos desprivilegiados. A desigualdade de acesso à discussão pública é uma forma de deslegitimação dos grupos sociais politicamente dominados (MIGUEL, 2014).

Existe o entendimento segundo o qual o parlamento é o único local adequado para abrigar o debate público e que os diferentes interesses sociais possuem representantes entre os parlamentares (MIGUEL, 2014). Essa concepção está equivocada, porque negligencia a distinção entre poderes constituídos e poder constituinte enquanto esferas simultaneamente discursivas e decisórias. Dos poderes constituídos, o parlamento é o principal local e o detentor de maior legitimidade democrática para abrigar o debate público e atuar como esfera decisória; porém, a centralidade do legislativo dentre os poderes constituídos continua a necessitar do poder constituinte, do próprio povo, que, na condição de soberano, também abrigam a esfera discursiva e decisória. Por essa razão, esses instrumentos destinados a tornar a democracia uma realidade exigem uma maior participação política popular. 


\section{CONSIDERAÇÕES FINAIS}

Desde a antiguidade até os dias de hoje, a democracia esteve fundamentada na liberdade e na igualdade. Embora diversos filósofos políticos não tenham pretendido promover uma defesa dos ideais democráticos, as teorias que formularam foram gradativamente assimiladas pela teoria da democracia. Nesse sentido, a liberdade consiste na capacidade intelectual do ser humano de realizar escolhas de forma consciente e por intermédio de um processo de reflexão e na possibilidade real de atuar em conformidade com a vontade formulada. De outro modo, a igualdade significa que a existência de um conjunto de caraterísticas básicas em comum que confere valor moral a todos os seres humanos, independentemente de diferenças culturais, biológicas e patrimoniais. Sustentar que as pessoas são iguais significa defender que são semelhantes em relação aos aspectos relevantes, apesar das diferenças existentes. Como consequência, a igualdade proporciona ainda o reconhecimento de autonomia moral para a larga maioria das pessoas que constituem uma sociedade. O indivíduo moralmente autônomo é, então, considerado suficientemente qualificado para realizar as próprias escolhas morais.

As vantagens da vida coletiva foram responsáveis por pressões evolucionárias que selecionaram características e incentivaram a sociabilidade humana. A estrutura neural que fomentava o autocuidado e a procura pelo bem-estar próprio foi gradativamente reformulada para abranger o cuidado e o bem-estar do outro. No início, o outro representou apenas a prole, mas, em seguida, houve uma ampliação proporcional à expansão do círculo de interação social até abranger parentes, companheiras e companheiros, amigos e até estranhos. A sociabilidade foi a base para o desejo de pertencimento a um grupo social e o desenvolvimento de uma consciência ligada a práticas sociais fortemente regulada por um sistema de aprovação e desaprovação estruturado por normas sociais. Na medida que o sistema de recompensa negativo regula a dor, o medo e a ansiedade e responde à desaprovação, e o sistema de recompensa positivo regular o prazer e responde à aprovação e à afeição, a ideia de apego subscrita pelo prazer da companhia e pela dor da separação constitui a plataforma neural da moralidade.

A natureza social do ser humano gera um problema prático para a teoria da democracia, tendo em vista que requer a compatibilização entre a liberdade e a igualdade de cada um dos membros de uma sociedade. A resolução desse impasse pode ser encontrada na própria ideia de sociabilidade humana. As normas sociais, a moralidade e o direito são frutos da construção de consensos coletivos, implícitos ou explícitos. Assim, em uma democracia, a soberania popular reside na autonomia política e na capacidade de autogoverno pelas quais o povo exerce o poder legislativo e dita para si as leis que regulam o comportamento humano. Dessa maneira, a liberdade pode ser também compreendida como a participação, em igualdade de condições, nos processos deliberativos públicos. No contexto em que existe uma alta probabilidade de pessoas igualmente livres formularem normas sociais e juízos morais diversos, as leis assumem a importante função de identificar, de modo relativamente claro e expresso, as opções realizadas por uma comunidade e reduzir a possibilidade de arbítrio.

Nos Estados contemporâneos, a representação política se tornou um instrumento essencial para a democracia, em virtude de três fatores principais: o tamanho das sociedades políticas impediu 
a união de todos os cidadãos em praça pública, tal como ocorria na Grécia antiga; a inclusão de grupos sociais historicamente excluídos intensificou essa dificuldade quantitativa; e o tempo disponível para a participação política foi sensivelmente reduzido, tendo em vista a necessidade de os cidadãos exercerem uma atividade laboral para a automanutenção. A representação política exerce papel central na estruturação das comunidades políticas e pode ser compreendida em sentido amplo e em sentido estrito. A representação política em sentido amplo inclui todos os agentes públicos, na medida que somente possuem essa condição pelo reconhecimento e pelo consentimento do povo. A representação política em sentido estrito consiste no corpo de representantes eleitos diretamente pelo povo para integrar o parlamento. Nesse contexto, o legislativo detém maior legitimidade democrática por três motivos: é constituído para representar a diversidade social; os legisladores são escolhidos diretamente pelo povo e estão sujeitos à responsabilização política periódica; e viabiliza a liberdade como autodeterminação política.

Esse modelo ideal de representação, todavia, quando trazido para a prática política, apresenta profundas distorções responsáveis por uma crise do sistema representativo, que atinge o parlamento e os partidos políticos. A consequência desse quadro é o surgimento de um déficit de legitimidade democrática. Sem negar a existência de outras, identificamos algumas opções que podem ser exploradas com o intuito de solucionar esse problema nas democracias. Em primeiro lugar, as distorções constantes na representação política em sentido estrito poderiam ser corrigidas com mecanismos que aprimorassem a representação proporcional e promovessem a seleção de representantes em grupos sociais minoritários ou excluídos. Em segundo lugar, a difusão de uma cultura democrática, com a conscientização de direitos e deveres e o fornecimento de condições materiais mínimas para a participação política do povo. Em terceiro lugar, os diversos grupos sociais devem possuir a oportunidade de participar do debate público e das escolhas morais, além de realizar a inclusão e a exclusão de temas da agenda pública. Em quarto lugar, os meios de comunicação precisam ser estruturados com o objetivo de garantir a manifestação dos diversos grupos sociais de interesse a fim de viabilizar a formação da opinião pública a partir do embate de argumentos.

\section{REFERÊNCIAS}

ALBUQUERQUE, Newton de Menezes. Estado brasileiro e modernidade periférica: limites e possibilidades da democracia na era da globalização. Pensar, Fortaleza, v. 15, n. 2, p. 535-556, jul./dez. 2010.

AUTOR. A política da presença para as mulheres. In: AUTOR (Org.). Democracia, igualdade e liberdade: perspectivas jurídicas e filosóficas. Lumen Juris: Rio de Janeiro, 2015, pp. 31-86.

ARISTÓTELES. Ética a Nicômaco. 4. ed. São Paulo: Nova Cultural, 1991.

BARRETT, Louise; DUNBAR, Robin; LYCETT, John. Evolutionary psychology. Oxford: Oneworld Publications, 2012.

BOCCHINI, Bruno. Pesquisa: cai a confiança no judiciário, no governo e nos partidos políticos. EBC (Agência Brasil), 12/06/15. Disponível em: <http://www.ebc.com.br/noticias/2015/06/pesquisa-caiconfianca-no-judiciario-no-governo-e-nos-partidos-politicos>. Acesso em: 6 out. 2015. 
CARTER, Ian. Positive and negative freedom. Stanford Encyclopedia of philosophy. Disponível em: <http://plato.stanford.edu/entries/liberty-positive-negative/\#OneConLibFreTriRel>. Acesso em: 11 fev. 2015.

CHURCHLAND, Patricia. Braintrust: What neuroscience tells us about morality. New Jersey: Princeton University Press, 2011.

COMPARATO, Fábio Konder. Ética - direito, moral e religião no mundo moderno. São Paulo: Companhia das Letras, 2010.

DAHL, Robert Alan. democracy and its critics. New Haven: Yale University Press, 1989.

DWORKIN, Ronald. Taking rights seriously. Nova lorque: Bloomsbury, 2013.

FERNANDEZ, Atahualpa; FERNANDEZ, Marly. Neuroética, direito e neurociência - conduta humana, liberdade e racionalidade jurídica. Curitiba: Juruá, 2008.

GOSEPATH, Stefan. Equality. The Stanford Encyclopedia of Philosophy. Disponível em: <http://plato.stanford.edu/entries/equality/\#ValEquWhyEqu>. Acesso em: 27 fev. 2015.

GOYARD-FABRE, Simone. O que é democracia?. São Paulo: Martins Fontes, 2003.

HOBBES, Thomas. O leviatã. 3. ed. São Paulo: Ícone, 2008.

JORGE, Marco Antonio Coutinho. Fundamentos da psicanálise - de Freud a Lacan: as bases conceituais. Rio de Janeiro: Zahar, 2014.

KANT, Immanuel. Fundamentação da metafísica dos costumes. Lisboa: Edições 70, 1986.

KELSEN, Hans. A democracia. Martins Fontes: São Paulo, 2000.

LOCKE, John. Two treatises of government and a letter concerning toleration. New Haven: Yale university Press, 2003.

MAQUIAVEL, Nicolau. O príncipe. São Paulo: Martin Claret, 2015.

MIGUEL, Luís Felipe. Democracia e representação: territórios em disputa. São Paulo: Unesp, 2014. Sorteios e representação democrática. Lua Nova, n. 50, 2000.

MOISÉS, José Álvaro. Os brasileiros e a democracia. São Paulo: Ática, 1995.

O'CONNOR, Timothy. Free will. The Stanford Encyclopedia of Philosophy. Disponível em: <http://plato.stanford.edu/archives/fall2014/entries/freewill/>. Acesso em: 5 fev 2015.

MONTESQUIEU. O espírito das leis. 3. ed. São Paulo: Martins Fontes, 2005.

RANCIÈRE, Jacques. O ódio à democracia. São Paulo: Boitempo, 2014.

ROUSSEAU, Jean-Jacques. O contrato social - princípios do direito político. São Paulo: Edipro, 2013.

SARLET, Ingo Wolfgang. A eficácia dos direitos fundamentais - uma teoria geral dos direitos fundamentais na perspectiva constitucional. 10. ed. Porto Alegre: Livraria do Advogado, 2011.

WALDRON, Jeremy. The dignity of legislation. Nova Iorque: Cambridge University Press, 1999.

\section{COMO CITAR ESSE DOCUMENTO:}

SOUZA, Cristiane Fernandes de; SOUZA, Paulo de Tarso Fernandes de. Direito e democracia - o significado das leis e do legislativo na teoria da democracia. Revista do Direito, Santa Cruz do Sul, v. 1 n. 51, jul. 2017. ISSN 1982-9957. Disponível em: <https://online.unisc.br/seer/index.php/direito/article/view/7784>. Acesso em: doi:http://dx.doi.org/10.17058/rdunisc.v1i51.7784. 